\title{
Diabetes Mellitus in Elkhounds Is Associated with Diestrus and Pregnancy
}

\author{
T. Fall, Å. Hedhammar, A. Wallberg, N. Fall, K.M. Ahlgren, H.H. Hamlin, K. Lindblad-Toh, \\ G. Andersson, and O. Kämpe
}

\begin{abstract}
Background: Female Elkhounds are shown to be at increased risk for diabetes mellitus, and occurrence of diabetes during pregnancy has been described in several cases.

Hypothesis: Onset of diabetes mellitus in Elkhounds is associated with diestrus.

Animals: Sixty-three Elkhounds with diabetes mellitus and 26 healthy controls.

Methods: Medical records from 63 Elkhounds with diabetes were reviewed and owners were contacted for follow-up information. Blood samples from the day of diagnosis were available for 26 dogs. Glucose, fructosamine, C-peptide, growth hormone $(\mathrm{GH})$, insulin-like growth factor-1, progesterone, and glutamate decarboxylase isoform 65-autoantibodies were analyzed and compared with 26 healthy dogs. Logistic models were used to evaluate the association of clinical variables with the probability of diabetes and with permanent diabetes mellitus after ovariohysterectomy (OHE).

Results: All dogs in the study were intact females and 7 dogs $(11 \%)$ were pregnant at diagnosis. The 1st clinical signs of diabetes mellitus occurred at a median of 30 days (interquartile range [IQR], 3-45) after estrus, and diagnosis was made at a median of 46 days (IQR, 27-62) after estrus. Diabetes was associated with higher concentrations of GH and lower concentrations of progesterone compared with controls matched for time after estrus. Forty-six percent of dogs that underwent OHE recovered from diabetes with a lower probability of remission in dogs with higher glucose concentrations (odds ratio [OR], 1.2; $P=.03)$ at diagnosis and longer time (weeks) from diagnosis to surgery (OR, $1.5 ; P=.05)$.

Conclusions: Diabetes mellitus in Elkhounds develops mainly during diestrus and pregnancy. Immediate OHE improves the prognosis for remission of diabetes.
\end{abstract}

Key words: Growth hormone; Ovariohysterectomy; Progesterone.

$\mathbf{O}$ ver 50 years ago, Campbell ${ }^{1}$ and Wilkinson ${ }^{2}$ reported that, in female dogs, diabetes often develops shortly after estrus. Wilkinson recommended ovariohysterectomy (OHE) for diabetic female dogs, which was considered a radical treatment option at that time. ${ }^{2}$ In 1983, Eigenmann and colleagues ${ }^{3}$ reported 10 female dogs that had their initial diagnosis of diabetes mellitus 3-5 weeks after estrus. All 10 dogs had significantly increased concentrations of insulin and growth hormone $(\mathrm{GH})$ compared with other diabetic dogs (males and castrated females) and healthy dogs. Some of the dogs in that study recovered from their diabetic state after OHE.

No additional case series have been published on this specific subtype of diabetes (ie, diestrus diabetes) since 1983. The lack of publications probably is because of the

From the Department of Clinical Sciences, Swedish University of Agricultural Sciences, Uppsala, Sweden (T. Fall, Hedhammar, Wallberg, N. Fall, Hamlin); the Department of Medical Epidemiology and Biostatistics, Karolinska Institutet, Stockholm, Sweden (T. Fall); the Department of Medical Sciences, University Hospital, Uppsala University, Uppsala, Sweden (Ahlgren, Kämpe); the Broad Institute of MIT and Harvard, 7 Cambridge Center, Cambridge, MA (LindbladToh); and the Department of Animal Breeding and Genetics, Swedish University of Agricultural Sciences, Uppsala, Sweden (Andersson). This work was performed at the Department of Clinical Sciences, Swedish University of Agricultural Sciences, Uppsala, Sweden. Abstract presented at ECVIM, 2010.

Corresponding author: Tove Fall, Department of Medical Epidemiology and Biostatistics, Karolinska Institutet, PO Box 281, SE-17177 Stockholm, Sweden; e-mail: tove.fall@kv.slu.se.

Submitted April 29, 2010; Revised August 17, 2010; Accepted September 14, 2010.

Copyright $(02010$ by the American College of Veterinary Internal Medicine

$10.1111 / j .1939-1676.2010 .0630 . x$

$\begin{array}{ll}\text { Abbreviations: } \\ \text { GAD65 } & \text { glutamate decarboxylase isoform } 65 \\ \text { GH } & \text { growth hormone } \\ \text { IGF } & \text { insulin-like growth factor } \\ \text { IQR } & \text { interquartile range } \\ \text { OHE } & \text { ovariohysterectomy } \\ \text { OR } & \text { odds ratio } \\ \text { SCDMP } & \text { Swedish Canine Diabetes Mellitus Project }\end{array}$

increased number of elective spays in the western world. Diestrus diabetes, however, is considered quite common in the unspayed dog population, and the onset is believed to be triggered by the increase of progesterone and potentially also mammary-derived GH during diestrus. ${ }^{4,5}$ The hormonal phase of diestrus mimics pregnancy with respect to its length and hormone concentrations. In Sweden, only about $7 \%$ of the total dog population is spayed. ${ }^{6}$ We have reported previously that in the Swedish and Norwegian Elkhound breeds, diabetes mellitus is almost exclusively diagnosed in female dogs, accounting for $97 \%$ of reported cases in a population-based study, and we also have reported that Elkhounds are predisposed to gestational diabetes mellitus. ${ }^{7}$

This study assesses the hypothesis that the onset of diabetes mellitus in Elkhounds is associated with pregnancy, diestrus, or both and thereby may serve as a natural model for studies of this specific diabetes subtype. Furthermore, clinical characteristics are described including comparisons of relevant hormone concentrations in diseased and healthy dogs at the same stage of the estrus cycle. Potential immunoreactivity to glutamate decarboxylase isoform 65 (GAD65) was analyzed to 
further elucidate the etiology. Factors affecting the chance of remission after OHE are evaluated and discussed.

\section{Materials and Methods}

\section{Dogs}

Case Recruitment Process. Since October 2005, blood samples and medical information were collected systematically from dogs diagnosed with diabetes mellitus in the Swedish Canine Diabetes Mellitus Project (SCDMP). All Norwegian and Swedish Elkhounds (hereafter referred to as Elkhounds) with diabetes mellitus recognized in the SCDMP from October 2005 to July 2009 were included in the present study. Diagnosis in each diabetic dog was based on clinical signs and fasting hyperglycemia $>7 \mathrm{mmol} / \mathrm{L}(>125 \mathrm{mg} / \mathrm{dL})$ or postprandial hyperglycemia $>11 \mathrm{mmol} / \mathrm{L}(>200 \mathrm{mg} / \mathrm{dL})$. From 26 dogs, sera were available from the day of diagnosis. Fasting status was variable at sampling.

Control Recruitment Process. Control dogs were recruited prospectively from 2007 to 2009 to the SCDMP by a personal letter to all owners of female intact Elkhounds born between 1998 and 2002 registered in the Swedish Kennel Club. Owners willing to participate in the study visited their local veterinarian 3-8 weeks after estrus. To be included as healthy controls in the SCDMP, dogs had to have normal fasting blood glucose and fructosamine concentrations at this visit. They also had to be free from clinical signs of diabetes according to the owners. Furthermore, all dogs were clinically examined by the local veterinarian following a specific protocol. For the present study, 26 control dogs were selected from the SCDMP database to match cases with respect to group mean of age, sex, and time after estrus at sampling.

Data collected from medical records and questionnaires included: date of birth, end date of last estrus bleeding, date of onset of clinical signs of diabetes, date of diagnosis, blood chemistry and urinalysis results, clinical signs at diagnosis, type and duration of treatment, body weight at diagnosis, date of remission if any, latest contact with a veterinarian, cause and date of death. Dog owners also were contacted for information on survival. The Swedish Kennel Club registry was accessed for confirmation of birth dates and pedigree information. If medical records were missing, dogs were excluded from the study. For the hormone analysis study, only dogs that were sampled on the day of diagnosis were included.

All sampling of dogs was approved by the owners by written consent, the Swedish Animal Ethical Committee (no. C267/5), and the Swedish Animal Welfare Agency (no. 2005-2038).

Clinical Pathology. Blood samples were drawn from the cephalic vein into tubes without anticoagulant. Within an hour of sampling, serum was separated and sent at ambient temperature to the Clinical Pathology Laboratory, University Animal Hospital at the Swedish University of Agricultural Sciences. Upon arrival at the laboratory, the samples were stored at $-80^{\circ} \mathrm{C}$ until analysis. Samples analysed at a 2nd laboratory (Clinical Pathology Laboratory, Utrecht University) were sent on dry ice from the primary laboratory.

Sera were analyzed at the Clinical Pathology Laboratory, University Animal Hospital at the Swedish University of Agricultural Sciences (C-peptide, fructosamine, progesterone, glucose, and insulin) and the Clinical Pathology Laboratory, Utrecht University (GH, and insulin-like growth factor-1 [IGF-1]). Serum glucose concentrations were determined by a glucose hexokinase method. ${ }^{\text {a }}$ Fructosamine was measured by a colorimetric assay, based on the ability of ketoamines to reduce nitrotetrazolium blue formazans in an alkaline medium. ${ }^{\text {b }}$ Progesterone concentrations were determined by a solid-phase, competitive chemiluminescent enzyme immunoassay. ${ }^{c}$ C-peptide was measured with a commercially available radioimmunoassay for canine $\mathrm{C}$-peptide. ${ }^{\mathrm{d}}$ The instructions given for the kit were followed accurately, except that the protease inhib- itor aprotinin ${ }^{\mathrm{e}}$ was added just before analysis instead of immediately after sampling as earlier described by Fall et al. ${ }^{8} \mathrm{GH}$ was analyzed with a commercially available RIA for porcine and canine $\mathrm{GH}^{\mathrm{f}}$ as described earlier by Beijerink et al. ${ }^{9}$ Serum IGF-1 concentrations were measured by an in-house RIA, originally designed for use on human sera, after acid-ethanol extraction to remove interfering IGF binding proteins as described in detail by Favier et al. ${ }^{10}$

In Vitro Transcription and Translation of GAD65 and Immunoprecipitation. A pCMV6 entry plasmid carrying a T7 promoter sequence and GAD2, ${ }^{11}$ the gene encoding canine GAD65, was designed and purchased from Origene. ${ }^{\mathrm{g}}$ The sequence of the insert was confirmed and used for in vitro transcription and translation into a radioactively labeled protein. The size of the protein was confirmed to be $65 \mathrm{kDa}$ on a precast BioRad Criterion gel. ${ }^{\mathrm{h}}$ Immunoprecipitations were performed as earlier described ${ }^{12}$ with sera from cases and controls. Two GAD65-positive human sera were used as positive controls.

Statistical Methods. Data are expressed as median and interquartile range (IQR). A graph of the Kaplan-Meier survivor function is used to display survival time after diagnosis. Dogs that were alive at the end of the study period were censored at the time of last registered contact. A $\chi^{2}$ test was used to evaluate if there was a significant difference between cases and controls concerning frequency of mammary tumors. The nonparametric Wilcoxon ranksum test was used to evaluate potential differences in different blood chemistry variables at diagnosis.

Two separate logistic models were examined: outcome of treatment classified as permanent diabetes or remission (treatment model) and whether or not progesterone and GH concentrations were associated with disease status (hormone model). In the treatment model, the predetermined predictor variables were days from onset of clinical signs to surgery (OHE), glucose concentration at diagnosis, and owner's perception of weight loss classified as yes or no. In the hormone model, the predetermined predictor variables were blood concentrations of $\mathrm{GH}$ and progesterone and number of days from end of estrus to blood sampling. Because GH and progesterone had a skewed distribution, values were transformed to the natural logarithmic scale. To allow for nonlinear association, quadratic terms of the continuous variables were introduced and, to avoid colinearity, were centered. The predictive ability of the model was evaluated by a receiver-operating characteristic curve (ROC). Statistical significance was set at $P<.05$. All statistical analyses were performed by SAS 9.1.3.

\section{Results \\ Clinical Findings}

In total there were 63 eligible registered Elkhounds with diabetes mellitus in the SCDMP register at the time of the study. All were intact females at the time of diagnosis. Thirteen dogs had at least 1 parent animal in common with another dog. Fifty-one dogs were of the Swedish Elkhound breed and 11 were of the Norwegian Elkhound breed. One dog was a cross-breed of a Swedish and a Norwegian Elkhound. The dogs were diagnosed and treated at 29 different Swedish veterinary clinics and 1 Norwegian veterinary clinic. Dogs were followed until death or July 1, 2009. The median follow-up time was 198 days (IQR, 66-594) for the 51 dogs that survived 1 day or more after diagnosis. Seven dogs $(11 \%)$ were pregnant at diagnosis. When testing different variables among pregnant and nonpregnant dogs, no differences were found except for age of onset $(P=.0025$, with pregnant dogs being younger), and therefore nonpregnant and pregnant 
diabetic dogs were considered as 1 group in further analyses. No dogs were on estrus-preventing medications.

First clinical signs of diabetes occurred a median of 30 days (IQR, 3-45) after last estrus and dogs were diagnosed with diabetes mellitus with a median of 46 days (IQR, 27-62) after last estrus. A scatter plot of days after estrus to first clinical signs is shown in Figure 1 together with reported lengths of the stages of the estrus cycle. ${ }^{13}$ The owner complaints and clinical findings in the diabetic dogs are listed in Table 1.

Median age at diagnosis of the 63 diabetic dogs was 8.5 years (IQR, 7.9-10.1). Median weight of diabetic Swedish Elkhounds at diagnosis was $26 \mathrm{~kg}$ (IQR, 24-30) (7 observations missing) and for diabetic Norwegian Elkhounds was $19 \mathrm{~kg}$ (IQR, 17-21). Control Swedish Elkhounds $(\mathrm{n}=23)$ had a median weight of $26 \mathrm{~kg}(\mathrm{IQR}$, 23-28) and control Norwegian Elkhounds $(\mathrm{n}=3) 21 \mathrm{~kg}$ (IQR, 20-21). Eleven diabetic dogs (17\%) had palpable mammary masses at diagnosis. Seven control dogs $(27 \%)$ had palpable mammary masses $(P=.32$, compared with diabetic dogs).

\section{Clinical Pathology}

Blood samples were available from 26 diabetic dogs from the day of diagnosis before any treatment was initiated and from 26 healthy dogs sampled 3-8 weeks after estrus. Table 2 presents the glucose, fructosamine, Cpeptide, progesterone, $\mathrm{GH}$ and IGF-1-concentrations, and $P$-values from Wilcoxon's rank-sum tests. All dogs were negative for GAD65-auto-reactivity with either canine or human radiolabeled GAD65. Cases had significantly higher concentrations of glucose, fructosamine, and C-peptide than control dogs.

\section{Survival}

Median survival time after diagnosis was 571 days (95\% CI, 152-1,184). Figure 2 shows a graph of the Kaplan-Meier survival function for all dogs in the study ( $\mathrm{n}=63,32$ failures), for dogs with permanent diabetes after OHE ( $\mathrm{n}=21,9$ failures), and for dogs that recovered from diabetes after OHE ( $\mathrm{n}=18,2$ failures).

\section{Treatment}

Fourteen dogs $(22 \%)$ were euthanized within 7 days of diagnosis. Thirty-nine of the dogs in the study (62\%) un-

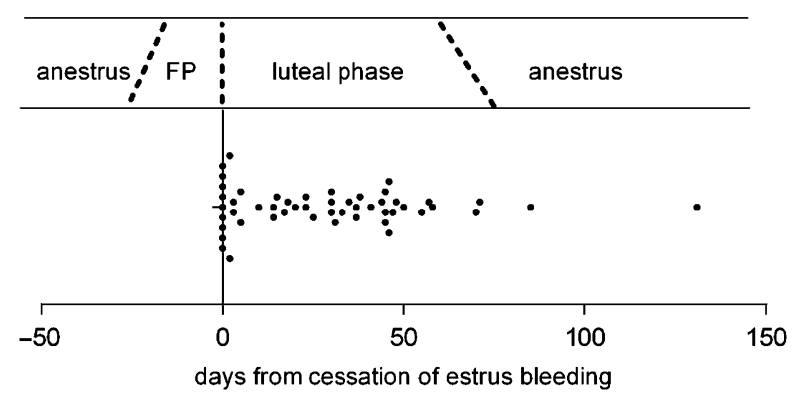

Fig 1. Onset of clinical signs of diabetes mellitus in Elkhounds compared with stage in estrus cycle. Days after end of estrus bleeding on $x$-axis. $\mathrm{PE} / \mathrm{E}$, proestrus/estrus.
Table 1. Owner complaints and clinical findings in $63 \mathrm{di}-$ abetic Elkhounds at day of diagnosis.

\begin{tabular}{lcc}
\hline & $\begin{array}{c}\text { Number of } \\
\text { Dogs }\end{array}$ & $\begin{array}{c}\text { Percent of Total Number of } \\
\text { Dogs }(\%)\end{array}$ \\
\hline $\begin{array}{l}\text { Polyuria and } \\
\text { polydipsia }\end{array}$ & 59 & 94 \\
Weight loss & 27 & 43 \\
Polyphagia & 10 & 16 \\
Pyometra & 11 & 17 \\
Cataract & 1 & 1.6 \\
Mammary tumors & 11 & 17 \\
Pregnancy & 7 & 11 \\
Ketonuria & 9 & 14 \\
\hline
\end{tabular}

derwent $\mathrm{OHE}$ and 34 of these were given insulin therapy either with intermediate-acting porcine insulin ${ }^{\mathrm{j}}$ or recombinant human NPH insulin. ${ }^{\mathrm{N}}$ One dog that did not undergo surgery was treated with insulin. Eighteen of 39 dogs $(46 \%)$ recovered from their diabetes after OHE and had normal glucose concentrations (after discontinuing insulin treatment in insulin-treated cases) a median of 11 days (IQR, 1-51) after surgery. Of the 10 dogs that were not treated by surgery and survived $>7$ days after diagnosis, only 1 recovered from diabetes. This dog had a new episode of diabetes after the next estrus and then was euthanized.

\section{Logistic Regression Models}

Results of the models are shown in Tables 3 and 4. None of the quadratic terms tested in the 2 models was significant, indicating a linear relationship of the continuous variables and the outcome variable. Hence, the quadratic terms were left out of the model. The ROC curve demonstrated moderate predictive ability of the models with areas under the curve of 0.86 and 0.76 , respectively.

In the hormone model, 6 dogs were excluded because of missing variables, hence 46 dogs were included. The model results from the log-transformed values are shown in Table 3. The odds ratio (OR) for $\mathrm{GH}$ on the log scale was 2.5 , indicating that an increase in $\mathrm{GH}$ from 5 to $10 \mu \mathrm{g} / \mathrm{L}$ is associated with an OR of 2.7 for diabetes. Similarly, an increase in progesterone from 10 to $20 \mathrm{nmol} / \mathrm{L}$ is associated with an OR of 0.53 for diabetes.

In the treatment model, 6 dogs were excluded because of missing variables, hence 33 dogs were included. The median glucose concentrations at diagnosis were $24 \mathrm{mmol} / \mathrm{L}$ (432 mg/dL) (IQR, 21-26) and $18 \mathrm{mmol} / \mathrm{L}$ (324 mg/dL) (IQR, 12-21) in the permanent diabetes and remission groups, respectively. The median time from onset of clinical signs to surgery was 4.4 weeks (IQR, 2.9-7.7) in the permanent diabetes mellitus group and 2.4 weeks (IQR, 1.4-3.9) in the remission group. Seven of $17(41 \%)$ dogs included in the model with permanent diabetes mellitus had lost weight whereas 2 of 16 $(13 \%)$ dogs had lost weight in the remission group. 
Table 2. Descriptive statistics of different blood parameters in 26 diabetic Elkhounds and 26 healthy control Elkhounds, matched on age and stage in estral cycle.

\begin{tabular}{lcccc}
\hline & Unit & Case Group (median, IQR) & Control Group (median, IQR) & Wilcoxon's Rank-Sum Test \\
\hline Glucose & $\mathrm{mmol} / \mathrm{L}$ & $19.9(14.2-26.9)$ & $5(4.5-5.4)$ & $P<.001$ \\
Fructosamine & $\mu \mathrm{mol} / \mathrm{L}$ & $529(345-866)$ & $301(289-334)$ & $P<.001$ \\
Progesterone & $\mathrm{nmol} / \mathrm{L}$ & $11(4-24)$ & $21(11-29)$ & $\mathrm{NS}$ \\
C-peptide & $\mathrm{nmol} / \mathrm{L}$ & $0.17(0.08-0.40)$ & $0.07(0.03-0.19)$ & $P=.02$ \\
GH & $\mu \mathrm{g} / \mathrm{L}$ & $6.8(4.3-18.5)$ & $5.1(4.1-7.5)$ & $\mathrm{NS}$ \\
IGF-1 & $\mu \mathrm{g} / \mathrm{L}$ & $138(61-369)$ & $156(108-312)$ & $\mathrm{NS}$ \\
Age at sampling & Years & $8.5(7.9-10.1)$ & $8.4(7.9-9.9)$ & $\mathrm{NS}$ \\
Days after last estrus (sample) & Days & $46(25-61)$ & $40(32-52)$ & $\mathrm{NS}$ \\
\hline
\end{tabular}

NS, nonsignificant; GH, growth hormone; IGF-1, insulin-like growth factor-1; IQR, interquartile range.

\section{Discussion}

The main finding of this study is that the onset of diabetes mellitus in Elkhounds is dependent on the luteal phase of the estrus cycle and pregnancy. The study also adds important information on clinical characteristics of diestrus diabetes and shows that early OHE improves the chance for remission of diabetes. Based on the results of this study, more informed clinical decisions may be made. The study also indicates that genetic risk variants for various forms of canine diabetes are unequally distributed among dog breeds.

The clinical presentation of the dogs in this study with polyuria and polydipsia as main clinical signs is consistent with earlier reports of diabetes in the dog. ${ }^{14}$ The age at onset was somewhat higher than earlier reported for Elkhounds in a population-based study of Swedish dogs. In the present study, the onset of diabetes mellitus coincided with pyometra in 10 cases $(17 \%)$. The yearly risk of pyometra in female Swedish Elkhounds is estimated to be $2.5 \%$, and the breed is ranked as a high-risk breed for the disease. ${ }^{15}$ In a dog predisposed to diabetes, an episode of pyometra may worsen insulin resistance due to inflammation and consequently accelerate diabetes. ${ }^{16,17}$ Krook et al discussed a possible relationship between diabetes mellitus and pyometra, and indicated that the same breeds often are predisposed to the 2 diseases. ${ }^{18}$

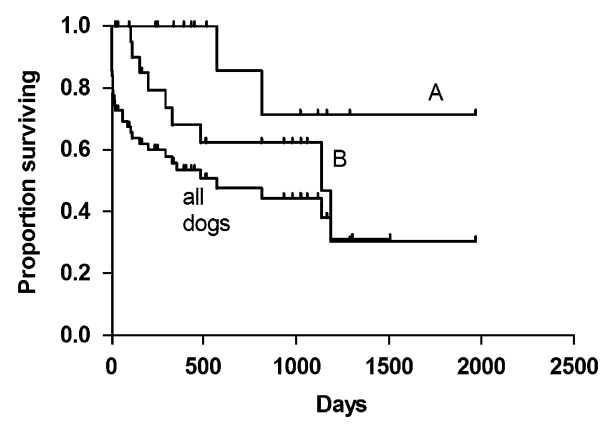

Fig 2. Kaplan-Meier survivor function for Elkhounds diagnosed with diabetes in the luteal phase. Ticks at time points at which dogs are censored. Lower curve shows all dogs. Curve B shows dogs with permanent diabetes after OHE and Curve A dogs, in which diabetes resolved after OHE.
There was a high prevalence of mammary tumors in the present study, both in diabetic dogs and controls, but no difference was found between the groups. Most of the dog owners were unaware of the tumors before the clinical examination. A high comorbidity of mammary tumors and diabetes within a breed such as the Elkhound could be explained by high mammary GH expression, which creates a proliferative environment in the mammary gland. ${ }^{19,20}$

In the present study, first clinical signs of diabetes occurred during pregnancy or during the diestrus phase in the present study, indicating an association with ovarian hormonal activity. Our hypothesis is that those Elkhounds that are predisposed by genetic factors and age to inadequate $\beta$-cell function, insulin resistance, high GH production or some combination of these things, develop diabetes during the progestational phases of the cycle. Somewhat surprisingly, in the present study, we found that diabetes was associated with lower progesterone concentrations compared with controls. This finding is not contradictory to our hypothesis because progesterone concentrations still were much higher than anestrus concentrations and apparently were high enough to stimulate GH secretion. ${ }^{3}$ Moreover, this finding is in agreement with a study of human GDM, in which progesterone was reported described to be lower than in healthy subjects, which may be due to lower luteal activity in the diabetic state. ${ }^{21}$

Several hormones such as progesterone, cortisol, and placental GH have been proposed to cause the insulin resistance seen in human pregnancies, but their separate functional roles and how they interact remain unclear. ${ }^{22-24}$ Physiologic insulin resistance plays an impor-

Table 3. Logistic regression of association of progesterone and growth hormone (log-transformed values) controlling for days from estrus to disease status in 26 diabetic dogs and 26 healthy controls.

\begin{tabular}{lccc}
\hline Variable & Odds Ratio & $95 \% \mathrm{CI}$ & $P$ Value \\
\hline Growth hormone $(\log \mu \mathrm{g} / \mathrm{L})$ & 2.5 & $1.2,6.0$ & .02 \\
Progesterone $(\log \mathrm{nmol} / \mathrm{L})$ & 0.2 & $0.1,0.6$ & .02 \\
Days from estrus & 1.0 & $1.0,1.0$ & .92 \\
\hline
\end{tabular}

CI, confidence interval. 
Table 4. Logistic regression of probability of permanent diabetes mellitus after ovariohysterectomy in 33 dogs with diestrus diabetes.

\begin{tabular}{lclc}
\hline Variable & Odds Ratio & $95 \%$ CI & $P$ Value \\
\hline Glucose $(\mathrm{mmol} / \mathrm{L})$ & 1.2 & $1.0,1.5$ & $\mathbf{. 0 3}$ \\
Weight loss, yes versus no & 2.2 & $0.3,17.0$ & .44 \\
Time in weeks from onset of & 1.5 & $1.0,2.2$ & $\mathbf{. 0 5}$ \\
symptoms to OHE & & & \\
\hline
\end{tabular}

CI, confidence interval; OHE, ovariohysterectomy.

tant role in fetal growth. ${ }^{25}$ In humans, a placental version of $\mathrm{GH}$ is produced in the placenta, which substitutes for pituitary production during pregnancy. ${ }^{26}$ The situation differs in dogs, in which it is the mammary gland that produces $\mathrm{GH}$ under progesterone influence. ${ }^{27}$ Little is known about placental production of the hormones mentioned above in dogs, and it is plausible that mammary production of $\mathrm{GH}$ substitutes for placental production, with the difference of being secreted even in nonpregnant luteal phases. Normal cycling nonpregnant female dogs have an altered profile of blood concentrations of $\mathrm{GH}$ during the luteal phase of the estrus cycle with less pulsatility and higher basal secretion due to mammary secretion of $\mathrm{GH}^{28}$ and that $\mathrm{GH}$ and insulin concentrations are higher in older compared with younger dogs after injection of progestins. ${ }^{29}$ In the present study, both cases and controls had higher concentrations of GH and IGF-1 than did anestrus dogs in a recent study by Beijerink et al using the same assays. ${ }^{9}$ However, the differences in GH concentrations between cases and controls in the present study were nominally much smaller than in an earlier study by Eigenmann et al on diestrus diabetes in which all diabetic dogs were clearly acromegalic. ${ }^{3}$ The study by Eigenmann et al differed from the present study in several aspects, such as the lack of breed- and estrus cycle-matched controls. Breed designations of the studied dogs were not indicated in the paper by Eigenmann et al, but the study was unlikely to have included many Elkhounds, which are mostly found in Scandinavia and North America. Furthermore, a different assay for measuring $\mathrm{GH}$ was used in that study.

All dogs in the study were negative for GAD-65autoantibodies, indicating a nonautoimmune etiology. Presence of such auto-antibodies earlier was reported in some dogs presumed to have autoimmune permanent diabetes and children with type 1 diabetes, but not in women with classical gestational diabetes or type 2 diabetes. ${ }^{30,31}$

$\mathrm{C}$-peptide is secreted together with insulin and has marginal hepatic uptake and a long half-life, which makes it a better marker of insulin release than measuring insulin itself. $^{32}$ In the present study, there was large variability in C-peptide concentrations in diabetic dogs, which indicates that the dogs may have been in different stages of disease at diagnosis and therefore may have had variable loss of $\beta$-cell function. ${ }^{33}$ This finding differs from that of Montgomery and others who showed that most diabetic dogs do not have a significant C-peptide secretion. ${ }^{34}$ However, many of these dogs were tested a long time after diagnosis, and no information was given on sex or breed designations. We showed earlier that some female dogs that later recovered from diabetes had high $\mathrm{C}$-peptide concentrations at diagnosis. ${ }^{8}$ The finding that $\mathrm{C}$-peptide was higher in cases than controls in the present study is difficult to interpret because all controls were fasted whereas some cases had eaten before sampling. Beta cells, however, can be assumed to be stimulated in all cases, because of the hyperglycemia. Diabetic dogs had higher glucose and fructosamine concentrations than did controls, which was expected.

An optimal study design to thoroughly study the hormonal changes in the diestrus diabetic state would include stimulation tests or frequent serial sampling. However, with the current study design, it was not possible to standardize sampling according to last feeding. To our knowledge, ours is the 1st study to give support to the hypothesis that dogs with diestrus diabetes should be treated as soon as possible after the first onset of clinical signs to avoid development of permanent diabetes mellitus. Progesterone and progesterone-induced mammary GH secretion decrease tissue sensitivity to insulin, inducing hyperglycemia if insulin secretion is insufficient. Dogs generally seem to be sensitive to glucose toxicity and lose their $\beta$ cell mass quickly if challenged with hyperglycemia. Imamura et al showed that a hyperglycemic clamp of $14 \mathrm{mmol} / \mathrm{L}(250 \mathrm{mg} / \mathrm{dL})$ in partially depancreatized dogs caused permanent diabetes within 2 weeks. ${ }^{35}$ Many diabetic dogs therefore are insulinopenic at diagnosis, and dependent on insulin for survival regardless of the cause of diabetes. ${ }^{8,34}$ In about half of the cases in the present study, diabetes became permanent although dogs underwent OHE. This outcome was probably due to chronic stress on $\beta$ cells caused by glucotoxicity. A reliable estimate of insulin secretion would be helpful to clinicians using methods such as the glucagon stimulation test. ${ }^{8,34}$ In the present study, insufficient samples were available to include fasting $\mathrm{C}$-peptide in the outcome model. High glucose concentrations affected the outcome of treatment negatively and may reflect $\beta$ cell exhaustion or $\beta$ cell death. In Sweden, OHE traditionally is employed for spaying procedures instead of the less invasive procedure of ovariectomy. Based on earlier reports, we suggest that an ovarioectomy (traditional midline incision or laparoscopic ${ }^{36}$ ) could be used instead of OHE for the treatment of diestrus diabetes, as long as there is not any evidence of uterine pathology. ${ }^{37}$ Bhatti et al has shown that the increase in GH concentrations stimulated by progestin also may be reversed by the progesteroneantagonist aglepristone, which could be a short-term alternative to early spaying. ${ }^{38}$

The number of Elkhounds euthanized at diagnosis in our previous epidemiologic study was estimated to be $70 \%$ and in the present study to be $22 \% .{ }^{4}$ This discrepancy is due to the fact that recruitment of dogs for the present study was biased toward dogs with longer postdiagnostic survival and lower frequency of euthanasia. This limitation of the study is explained by the fact that it is inherently easier to get samples and acquire 
information from dogs that live longer. Hence, the success rate of $46 \%$ recovery after OHE may be an optimistic estimate.

Gestational diabetes is a major human health problem and increases the risk for premature births, congenital malformations, macrosomia, and fetal death. ${ }^{39,40}$ There are large ethnic differences in the incidence of gestational diabetes and mothers with a family history of diabetes exhibit a higher risk, which demonstrates that strong genetic factors are involved. ${ }^{41,42}$ Obesity and old age are 2 other well-known risk factors for GDM in humans. ${ }^{41,43}$

With this report, we have characterized diestrus diabetes in Elkhounds. The larger-sized Swedish Elkhound and the smaller-sized Norwegian Elkhound are 2 hunting breeds that were classified as of the same breed until 1947. The incidence of diabetes has been reported to be lower in Norwegian than in Swedish Elkhounds but with the same female predisposition. ${ }^{4}$ From the results of this study, we conclude that certain breeds may be predisposed to specific forms of diabetes. This may be caused by genetic variants accumulated in these breeds, either by "hitch-hiking" effects through linkage with other desirable genes or by direct beneficial effects giving the animal a survival advantage, such as better reproductive capabilities in a cold climate.

The purebred dog is ideally suited for comparative studies aimed at identifying genetic and environmental risk factors for spontaneous disorders with complex inheritance such as gestational diabetes, using even a low number of cases and controls. ${ }^{44}$ Our current cohort of diabetic dogs and population-matched control dogs may allow identification of genetic risk factors as well as environmental risk factors underlying this syndrome. Thus, the naturally occurring dog model could be of considerable importance in understanding genetic and metabolic pathways leading to gestational diabetes in both dogs and humans.

\section{Footnotes}

${ }^{\text {a }}$ Glucose, Thermo Clinical Labsystems Oy, Vantaa, Finland

${ }^{\mathrm{b}} \mathrm{ABX}$ Pentra Fructosamine, ABX Diagnostics, Montpellier, France

${ }^{\mathrm{c}}$ Immulite 2000 Progesterone, Siemens Healthcare Diagnostics, Deerfield, IL

${ }^{\mathrm{d}}$ Canine C-peptide RIA, Linco Research, St Charles, MO

${ }^{\mathrm{e}}$ Trasylol, Bayer, Göteborg, Sweden

${ }^{\mathrm{f}} \mathrm{PGH}-46 \mathrm{HK}$; Linco Research

${ }^{\mathrm{g}}$ Origene, Rockville, MD

${ }^{\mathrm{h}}$ BioRad, Hercules, CA

${ }^{\mathrm{i}}$ SAS Institute Inc, Cary, NC

${ }^{\mathrm{j}}$ Caninsulin, Intervet, Danderyd, Sweden

${ }^{\mathrm{k}}$ Insulatard, Novo Nordisk, Bagsvaerd, Denmark

\section{Acknowledgments}

We acknowledge the help of Ms Helena Skarp, Swedish Kennel Club, with dog registration data. We also acknowledge Dr Åsa Juberget for help with case recruit- ment and for sharing her extensive knowledge about Elkhounds.

KLT is an ESF EURYI award recipient. This study was supported by the European Commission (FP7LUPA, GA-201370), Agria Pet Insurance Research Foundation and The Swedish Research Council. The funders had no role in study design, data collection and analysis, decision to publish, or preparation of the manuscript.

\section{References}

1. Campbell EA. The treatment and control of diabetes in the dog. Aust Vet J 1958;34:222-225.

2. Wilkinson JS. Spontaneous diabetes mellitus. Vet Rec 1960;72:548-555.

3. Eigenmann JE, Eigenmann RY, Rijnberk A, et al. Progesterone-controlled growth hormone overproduction and naturally occurring canine diabetes and acromegaly. Acta Endocrinol (Copenh) 1983;104:167-176.

4. Fall T, Hamlin HH, Hedhammar A, et al. Diabetes mellitus in a population of 180,000 insured dogs: Incidence, survival, and breed distribution. J Vet Intern Med 2007;21:1209-1216.

5. Eigenmann JE, Rijnberk A. Influence of medroxyprogesterone acetate (Provera) on plasma growth hormone levels and on carbohydrate metabolism. I. Studies in the ovariohysterectomized bitch. Acta Endocrinol (Copenh) 1981;98:599-602.

6. Egenvall A, Hedhammar A, Bonnett BN, et al. Survey of the Swedish dog population: Age, gender, breed, location and enrollment in animal insurance. Acta Vet Scand 1999;40:231-240.

7. Fall T, Johansson Kreuger S, Juberget A, et al. Gestational diabetes mellitus in 13 dogs. J Vet Intern Med 2008;22:1296-1300.

8. Fall T, Holm B, Karlsson A, et al. Glucagon stimulation test for estimating endogenous insulin secretion in dogs. Vet Rec 2008;163:266-270.

9. Beijerink NJ, Bhatti SF, Okkens AC, et al. Adenohypophyseal function in bitches treated with medroxyprogesterone acetate. Domest Anim Endocrinol 2007;32:63-78.

10. Favier RP, Mol JA, Kooistra HS, et al. Large body size in the $\operatorname{dog}$ is associated with transient $\mathrm{GH}$ excess at a young age. J Endocrinol 2001;170:479-484.

11. Arata S, Hashizume C, Kikusui T, et al. Sequences of canine glutamate decarboxylase (GAD) 1 and GAD2 genes, and variation of their genetic polymorphisms among five dog breeds. J Vet Med Sci 2008;70:1107-1110.

12. Alimohammadi M, Bjorklund P, Hallgren A, et al. Autoimmune polyendocrine syndrome type 1 and NALP5, a parathyroid autoantigen. N Engl J Med 2008;358:1018-1028.

13. Concannon PW, Hansel W, Visek WJ. The ovarian cycle of the bitch: Plasma estrogen, LH and progesterone. Biol Reprod 1975; 13:112-121.

14. Foster SJ. Diabetes mellitus - a study of the disease in the dog and cat in Kent. J Small Anim Pract 1975;16:295-315.

15. Egenvall A, Hagman R, Bonnett BN, et al. Breed risk of pyometra in insured dogs in Sweden. J Vet Intern Med 2001;15:530 538.

16. McLane MP, Tomasik TW, Law WR, et al. Hepatic insulin resistance during canine sepsis. Circ Shock 1991;33:207-215.

17. Park K, Steffes M, Lee DH, et al. Association of inflammation with worsening HOMA-insulin resistance. Diabetologia 2009;52:2337-2344.

18. Krook L, Larsson S, Rooney JR. The interrelationship of diabetes mellitus, obesity, and pyometra in the dog. Am J Vet Res 1960;21:120-127.

19. Kleinberg DL, Wood TL, Furth PA, et al. Growth hormone and insulin-like growth factor-I in the transition from normal mam- 
mary development to preneoplastic mammary lesions. Endocr Rev 2009;30:51-74.

20. Mol JA, van Garderen E, Selman PJ, et al. Growth hormone mRNA in mammary gland tumors of dogs and cats. J Clin Invest 1995; $95: 2028-2034$.

21. Montelongo A, Lasuncion MA, Pallardo LF, et al. Longitudinal study of plasma lipoproteins and hormones during pregnancy in normal and diabetic women. Diabetes 1992;41:1651-1659.

22. Barbour LA, Shao J, Qiao L, et al. Human placental growth hormone causes severe insulin resistance in transgenic mice. Am J Obstet Gynecol 2002;186:512-517.

23. Ryan EA, Enns L. Role of gestational hormones in the induction of insulin resistance. J Clin Endocrinol Metab 1988;67:341-347.

24. Kirwan JP, Hauguel-De Mouzon S, Lepercq J, et al. TNFalpha is a predictor of insulin resistance in human pregnancy. Diabetes 2002;51:2207-2213.

25. Catalano PM, Thomas AJ, Huston LP, et al. Effect of maternal metabolism on fetal growth and body composition. Diabetes Care 1998;21(Suppl 2):B85-B90.

26. Igout A, Scippo ML, Frankenne F, et al. Cloning and nucleotide sequence of placental hGH-V cDNA. Arch Int Physiol Biochim 1988;96:63-67.

27. Selman PJ, Mol JA, Rutteman GR, et al. Progestin-induced growth hormone excess in the dog originates in the mammary gland. Endocrinology 1994;134:287-292.

28. Kooistra HS, den Hertog E, Okkens AC, et al. Pulsatile secretion pattern of growth hormone during the luteal phase and midanoestrus in Beagle bitches. J Reprod Fertil 2000;119:217-222.

29. McCann JP, Altszuler N, Hampshire J, et al. Growth hormone, insulin, glucose, cortisol, luteinizing hormone, and diabetes in Beagle bitches treated with medroxyprogesterone acetate. Acta Endocrinol (Copenh) 1987;116:73-80.

30. Lernmark A, Baekkeskov S. Islet cell antibodies-theoretical and practical implications. Diabetologia 1981;21:431-435.

31. Davison LJ, Weenink SM, Christie MR, et al. Autoantibodies to GAD65 and IA-2 in canine diabetes mellitus. Vet Immunol Immunopathol 2008;126:83-90.

32. Polonsky KS, Pugh W, Jaspan JB, et al. C-peptide and insulin secretion. Relationship between peripheral concentrations of
C-peptide and insulin and their secretion rates in the dog. J Clin Invest 1984;74:1821-1829.

33. Faber OK, Binder C. C-peptide response to glucagon. A test for the residual beta-cell function in diabetes mellitus. Diabetes 1977;26:605-610.

34. Montgomery TM, Nelson RW, Feldman EC, et al. Basal and glucagon-stimulated plasma C-peptide concentrations in healthy dogs, dogs with diabetes mellitus, and dogs with hyperadrenocorticism. J Vet Intern Med 1996;10:116-122.

35. Imamura T, Koffler M, Helderman JH, et al. Severe diabetes induced in subtotally depancreatized dogs by sustained hyperglycemia. Diabetes 1988;37:600-609.

36. van Goethem B, Schaefers-Okkens A, Kirpensteijn J. Making a rational choice between ovariectomy and ovariohysterectomy in the dog: A discussion of the benefits of either technique. Vet Surg 2006;35:136-143.

37. Okkens AC, Kooistra HS, Nickel RF. Comparison of longterm effects of ovariectomy versus ovariohysterectomy in bitches. J Reprod Fertil Suppl 1997;51:227-231.

38. Bhatti SF, Duchateau L, Okkens AC, et al. Treatment of growth hormone excess in dogs with the progesterone receptor antagonist aglepristone. Theriogenology 2006;66:797-803.

39. Hod M, Merlob P, Friedman S, et al. Gestational diabetes mellitus. A survey of perinatal complications in the 1980s. Diabetes 1991;40(Suppl 2):74-78.

40. Casey BM, Lucas MJ, McIntire DD, et al. Pregnancy outcomes in women with gestational diabetes compared with the general obstetric population. Obstet Gynecol 1997;90:869-873.

41. Savitz DA, Janevic TM, Engel SM, et al. Ethnicity and gestational diabetes in New York City, 1995-2003. Br J Gynecol 2008;115:969-978

42. Retnakaran R, Connelly PW, Sermer M, et al. The impact of family history of diabetes on risk factors for gestational diabetes. Clin Endocrinol (Oxf) 2007;67:754-760.

43. Solomon CG, Willett WC, Carey VJ, et al. A prospective study of pregravid determinants of gestational diabetes mellitus. JAMA 1997;278:1078-1083.

44. Karlsson EK, Baranowska I, Wade CM, et al. Efficient mapping of mendelian traits in dogs through genome-wide association. Nat Genet 2007;39:1321-1328. 